\title{
Advanced Chemical Propulsion Study
}

\author{
Gordon Woodcock \\ Gray Research, \\ Huntsville, AL 35806 \\ Dave Byers \\ Science Applications International Corporation, \\ Torrance, CA 90505 \\ Leslie A. Alexander \\ NASA Marshall Space Flight Center, \\ Huntsville, AL 35812
}

Al Krebsbach

NASA Marshall Space Flight Center,

Huntsville AL 35812

The work described in this paper was funded in whole or in part by the In-Space Propulsion Technology Program, which is managed by NASA's Science Mission Directorate in Washington, D.C., and implemented by the In-Space Propulsion Technology Office at Marshall Space Flight Center in Huntsville, Ala. The program objective is to develop in-space propulsion technologies that can enable or benefit near and mid-term NASA space science missions by significantly reducing cost, mass or travel times. 


\title{
Advanced Chemical Propulsion Study
}

\author{
Gordon Woodcock" and Dave Byers ${ }^{\dagger}$ \\ *Gray Research, 655 Discovery Drive, Suite 300, Huntsville, AL 35806 USA, grw33@ comcast.net \\ †SAIC, ,4465 Pacific Coast Hwy, Torrance, CA90505 USA,byersdc@aol.comi \\ $-$ \\ Leslie A. Alexander \\ Code TD-05, Marshall Space Flight Center, NASA, Huntsville AL 35812
}

and

Al Krebsbach

Code TD-05, Marshall Space Flight Center, NASA, Huntsville AL 35812

\begin{abstract}
A study was performed of advanced chemical propulsion technology application to space science (Code S) missions. The purpose was to begin the process of selecting chemical propulsion technology advancement activities that would provide greatest benefits to Code $S$ missions. Several missions were selected from Code $S$ planning data, and a range of advanced chemical propulsion options was analyzed to assess capabilities and benefits re these missions. Selected beneficial applications were found for higher-portorming bipropellants, gelled propellants, and cryogenic propellants. Technology advancement recomm-endations included cryocoolers and small turbopump engines for cryogenic propellants; space storable propellants such as LOX-hydrazine; and advanced monopropellants. It was noted that fluorine-bearing oxidizers offer performance gains over more benign oxidizers. Potential benefits were observed for gelled propellants that could be allowed to freeze, then thawed for use.
\end{abstract}

\section{Introduction}

Chemical propulsion has been the mainstay of space exploration propulsion since the beginning of space missions. It is still the only technology applicable to launch from Earth to orbit, but a number of alternatives are emerging for in-space propulsion. In-space chemical propulsion has relied almost exclusively on two technologies since the beginning: Earth storable propellants, used as (1) bipropellants, and (2) monopropellants. Hydrazine has been the dominant and almost exclusive choice for monopropellant, and oxides of nitrogen, usually $\mathrm{N}_{2} \mathrm{O}_{4}$, with hydrazine compounds, have been the dominant and almost exclusive choice for bipropellants." Propellant delivery has been almost exclusively pressure-fed using helium pressurization of propellant tanks (a féw small pump-fed systems have flown). Ignition systems are not needed; the bipropellant combinations are hypergolic and hydrazine as a monopropellant is reliably decomposed by a catalyst.

- These systems are reliable; much experience and proven hardware designs exist; performance is reasonable, and operations experience has been good.

On the other hand, better-performing propellant combinations are known; the current propellants are toxic; and pressure-fed propellant delivery systems are comparatively high in inert mass due to the high pressures.

Space science missions are becoming more demanding on propulsion, thus needing better performance. One option is to introduce new tectnology such as electric propulsion or aerocapture. An alternative option is to improve the performance of current technology. The study reported here investigated this alternative option.

\section{Objectives of the Study}

1. Develop a workable description of "advanced chemical" propulsion technology and a suite of technology options applicable to Code $\mathrm{S}$ missions

2. Develop a preliminary assessment of the benefits of advanced chemical propulsion, relative to competing technologies, by technology option and versus mission characteristics or category 
3. Provide guidance for future more detailed systems analyses, and recommend technology advancement directions for future directed and competed technology advancement tasks.

4. Identify specific high-priority systems analysis areas of investigation.

\section{Mission Selection}

A small set of missions was selected as appropriate to achieving the objectives. The selected missions, and their reasons for selection, are as follows:

\begin{tabular}{|l|l|}
\hline \multicolumn{1}{|c|}{ Mission } & \multicolumn{1}{c|}{ Reason for Inclusion } \\
\hline $\begin{array}{l}\text { Neptune Obiter, } \\
\text { (capture, SEP/chem.) }\end{array}$ & High delta V, test benefits of cryogenics \\
\hline Venus Aeronomy & Modest delta V, small, test alternatives to conventional storable propellants \\
\hline Titan Explorer & Aerocapture baseline case for which state-of-the-art chemical propulsion almost works \\
\hline Titan Sample Retum & $\begin{array}{l}\text { Difficult mission, test cryogenics capability to do retum with aerocapture, also all- } \\
\text { propulsive option }\end{array}$ \\
\hline Telemachus & $\begin{array}{l}\text { Test ability of advanced chemical propuision to replace multiple inner solar system } \\
\text { gravity assists }\end{array}$ \\
\hline Solar Probe & Benefits of advanced chemical propulsion to replace STAR-48 as "C3 topper" \\
\hline
\end{tabular}

The C3 topper is a smaller upper stage added to a launch. vehicle to obtain higher launch energy than possible with the launch vehicle standard configuration. C3 is a measure of launch energy, the square of the so-called hyperbolic excess velocity.

Figures appended to this paper provide summary descriptions of these missions, taken from NASA Code S mission planning data. They do not represent approved missions, but were used as representative examples of potential future mission needs for purposes of analyzing benefits of advances in chemical propulsion technology

\section{Advanced Chemical Propulsion Options}

The study was structured to issues dealing with advantages and disadvantages of advanced chemical propulsion technology, both generically and for the specific missions in the mission set. In this paper we cover the most significant of these issues.

The study considered relatively few propellants among the hundreds of propellant combinations and variations that could be considered. The reference was $\mathrm{N}_{2} \mathrm{O}_{4}-\mathrm{MMH}$. We also considered gelled $\mathrm{N}_{2} \mathrm{O}_{4}-\mathrm{MMH}$. LOXhydrazine was used as representative of a space storable propellant with greater Isp. $\mathrm{LOX}-\mathrm{LH}_{2}$ represented highperformance deep cryogens.

Exotic propellants are exceptionally noxious substances that yield exceptional performance, especially high Isp with relatively dense propellants. We considered fluorine-bearing oxidizers as typical of this class. A review of fluorine-bearing oxidizers indicated that those with higher performance potential are mild cryogenics. The storable oxidizer $\mathrm{CLF}_{5}$ offers little Isp advantage. It is, however, very dense. We selected $\mathrm{OF}_{2}-\mathrm{MMH}$ as representative of the class.

Hybrids werre represented by a paraffin-like fuel loaded with a metallic hydride, using LOX as the oxidizer. Isp approaching 350 seconds is projected by the advocates.

Advanced monopropellants use hydrazine or amine-related compounds such as HAN, soluble in water or ionic liquids, together with fuel compounds, to produce a monopropellant that gets its energy from a combustion reaction rather than decomposition. Isp projections range from 225 to about 300 . We used 275 .

\section{Study Approach}

The study developed performance predictions for the propellants considered, and developed an initial version of a spread-sheet-based spacecraft propulsion system performance and mass model. The model was used for parametric as well as point-design calculations of systems performance. The parametric performance data were used to develop generic conclusions regarding advantages and disadvantages, and the point-design data were used to assess performance of the various propulsion systems on specific missions.

The model developed inert mass data, calculated propellant load requirements, and estimated payload and/or initial mass, parametrically and for specific mission cases. Heat leak for cryogenics with varying thickness of multilayer insulation (MLI), and performance and mass of cryocoolers, were included. Cryocoolers were assumed in all cryogenic cases. 


\section{Propellants Performance}

The TDK performance prediction code was used to estimate performance for $\mathrm{N}_{2} \mathrm{O}_{4}-\mathrm{MMH}$, LOX-hydrazine, $\mathrm{LOX}-\mathrm{LH}_{2}$, and $\mathrm{OF}_{2}-\mathrm{MMH}$. Calculations were made for chamber pressures $0.7,1.4$, and $3.5 \mathrm{MPa}(100,20 \mathrm{C}$ and 500 psia), area ratios 100 and 200 , and a range of mixture ratios. Axisymmetric inviscid calculation results were discounted $2 \%$ Isp for combustion inefficiency and $2 \%$ for viscous and divergence effects. Some modern spacecraft engines use area ratios approaching 400 . Most of our comparisons were based on area tatio 100 and chamber pressure $0.7 \mathrm{MPa}$. The increase in Isp at 400 area ratio is typically 10 seconds. Results of calculations are presented in Figures 1 - 6. For LOX- $\mathrm{LH}_{2}$ we used Isp 420 for pressure-fed systems and 445 for small pump-fed systems.

Uncertainties associated with small $\mathrm{LOX}-\mathrm{LH}_{2}$ systems are significant. Chamber pressure for pressure-fed systems will be quite low because of the mass penalties for pressurizing hydrogen, and the performance of pump-fed systems will depend on small pump performance and operating characteristics. The Isp estimates we used are believed to be somewhat conservative.

In comparing LOX-hydrazine to $\mathrm{N}_{2} \mathrm{O}_{4}-\mathrm{MMH}$, we noted that $\mathrm{N}_{2} \mathrm{O}_{4}$ - hydrazine is also an option yielding about 5 seconds more Isp than the reference.

State of the art for gelled propellants is as tactical missile propellants. IRFNA and UDMH or MMH have been successfully tested in prototype missile systems. Gellants reduce Isp but additives such as aluminum increase it. recovering the loss due to the gellants. Solid propellant gas generators (SPGGs) provide efficient, lightweight pressurization. We assumed the Isp loss by gallants would be compensated by other additives such as metals.

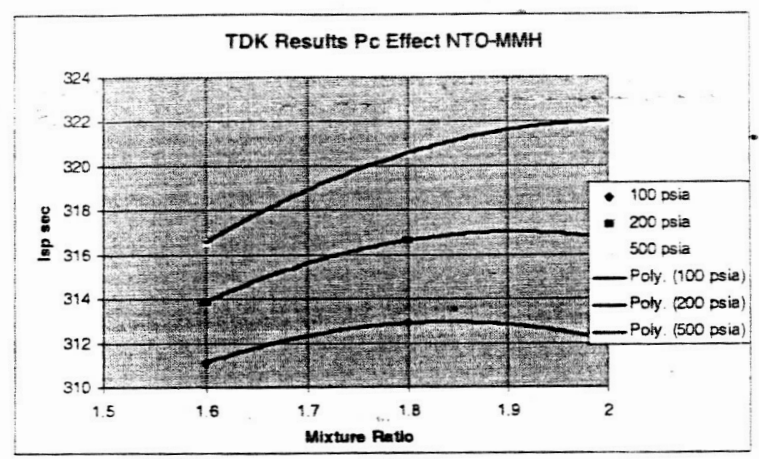

Figure 1 Isp for NTO-MMH

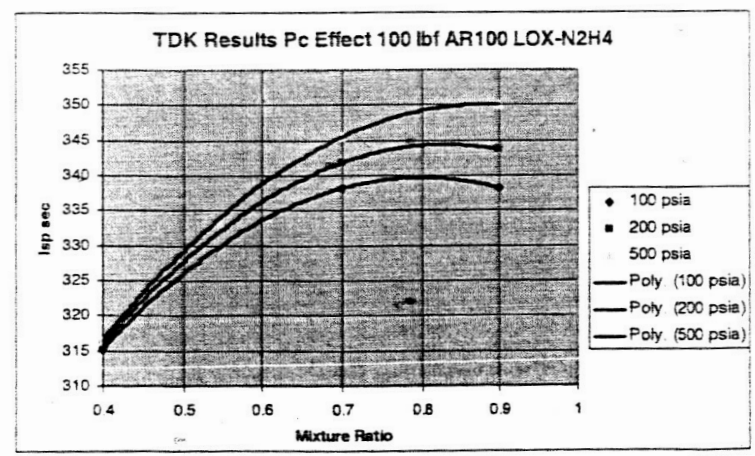

Figure 2 Isp for LOX-Hydrazine

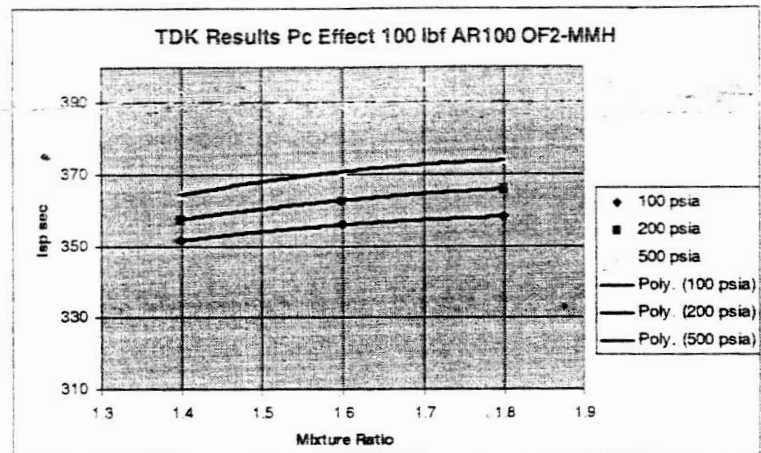

Figure 3 Isp for OF2-MMH

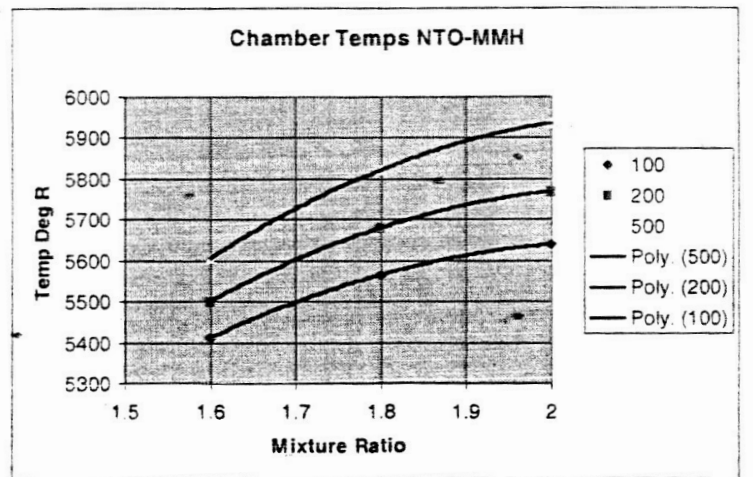

Figure 4 Chamber Temperatures NTO-MMH

\section{Overall Stack-Up:}

\section{Main Results}

Performance of the propulsion options is affected by space vehicle mass and other considerations discussed below. An overview of general performance trends is presented in Fig. 7. LOX-LH2 performance also varies significantly with system assumptions as described below; as shown here, a simple pressure-fed $\mathrm{LOX}^{-\mathrm{LH}_{2}}$ system with cryocoolers is not competitive. 


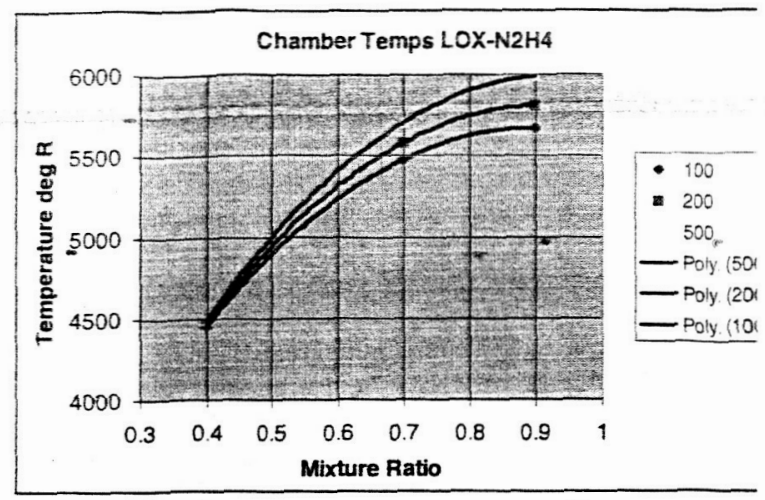

Figure 5 Chamber Temperatures LOX-Hydrazine

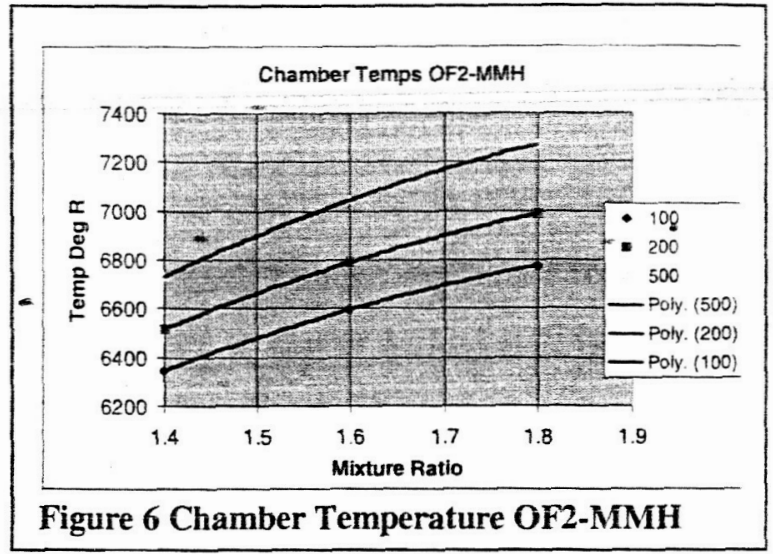

Figure 6 Chamber Temperature OF2-MMH

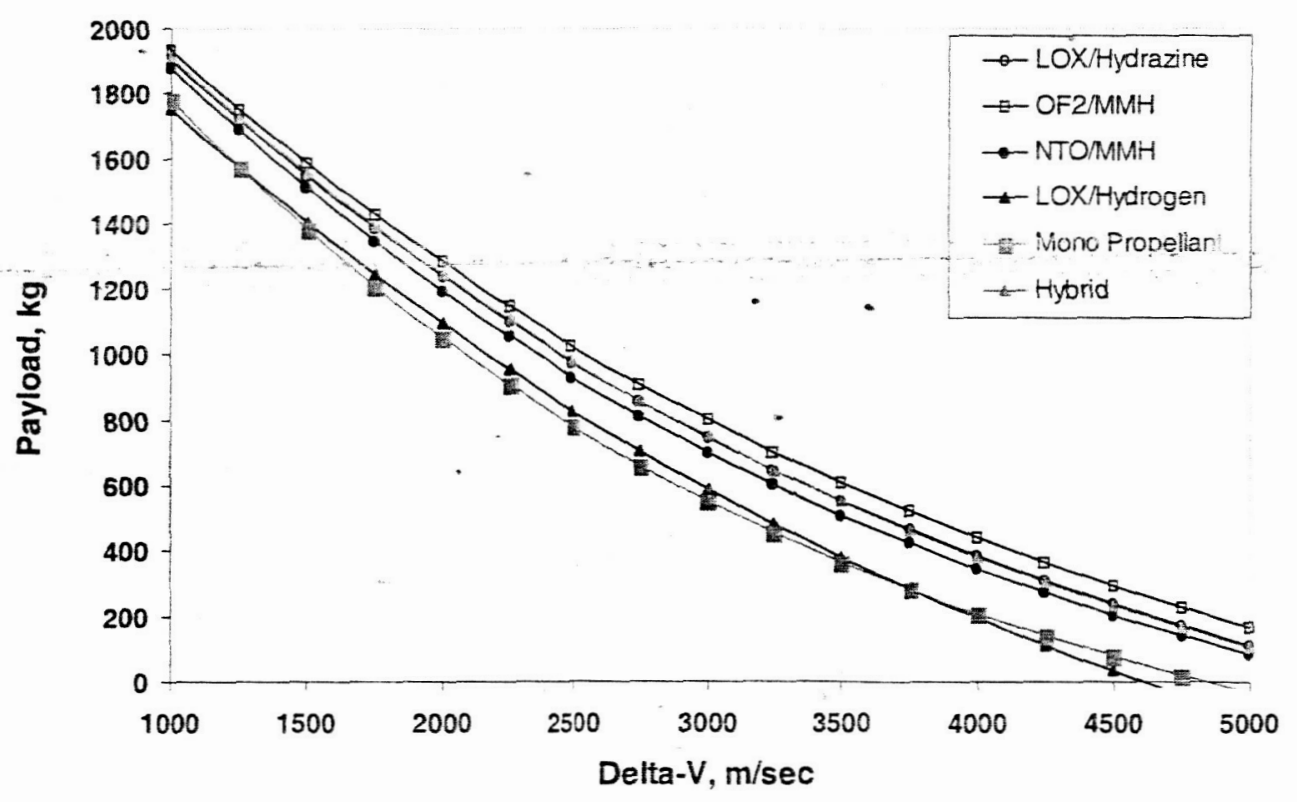

Figure 7 General Performance Trends for Advanced Chemical Propulsion

$\mathrm{OF}_{2}-\mathrm{MMH}$ is the highest-performing system. LOX-hydrazine and the advanced hybrid have essentially equal performance. The baseline is next, and monopropellants and $\mathrm{LOX}-\mathrm{LH}_{2}$ have the poorest performance.

The performance differences depicted here are not dramatic. At higher delta Vs, the best systems typically offer payload 20\%-50\% greater than the baseline. At lower delta Vs there is little motivation to adopt a new system, unless one were to selectt a monopropellant because of its relative simplicity. However, for a mature technology like chemical propulsion, even modest improvements can exhibit high leverage, especially for commercial users.

Fig. 8 shows inert mass trending for the propellants mainly considered in this study, above with full cryocooler mass penalty and below with no cryocooler mass penalty. The LOX-hydrogen system is low pressure pressure-fed in both cases; pump-fed systems exhibit somewhat less inert mass due to savings in pressurization and tank masses.

LOX-hydrazine - This combination suffers penalties relative to the baseline that tend to offset its higher Isp: (1) Overall lower density, slightly increasing tank and pressurization mass; (2) low temperature for LOX, requiring insulation, a greater mass of pressurization gas, and in most cases a cryocooler. Our analysis showed a modest net performance advantage. Fig. 9 presents a typical inert mass comparison with the baseline storables.

Cryocoolers - A space vehicle carrying a cryogenic propellant for more than a few months requires a cryocooler (refrigeration machine) to maintain the cryogen in a liquid state and prevent. boiloff. The cryocooler represents an 
inert mass penalty and requires power, which represents an additional mass penalty. For this study, we used cryocooler state-of-the-art from the literature, extrapolated as necessary to cover the range of power required. Fig. 10 shows curve-fit mass trending for cryocoolers.

The mass shown ${ }^{-}$is the cryocooler machine only. Mass estimates in the study included power and control electronics, the spower source (usually solar), and cooler thermal rejection. Heat leak into the cryogenic tank was calculated by an approximate formula for MLI, corrected for actual/theoretical heat leak ratio $\mathrm{f}=$ about 2 . Estimates for plumbing penetrations and tank supports were added. Subsequent research of references indicates the actual/theoretical ratio should be about $1.3-1.5$. Optimization of MLI for a typical hydrogen tank is shown in Fig. 11. Typical power requirements and distribution of mass are shown in Fig. 12. Future studies should estimate and evaluate anticipated improvements in cryocooler technology. Mass reduction and efficiency improvement are both very beneficial.

$$
Q=\sigma \sigma \varepsilon\left(T_{0}^{4}-T_{1}^{4}\right) / N_{\text {layers }}
$$

Cryogenic Propulsion - While missions up to some months' duration may be possible without cryocoolers, and mild cryogens such as liquid oxygen may be usable in a passively-cooled mode, for this study we assumed cryocoolers were needed for all missions involving cryogenic propellants, except the $\mathrm{C} 3$ topper. The significant mass penalty of cryocoolers reduces the performance potential for LOX-hydrogen systems.

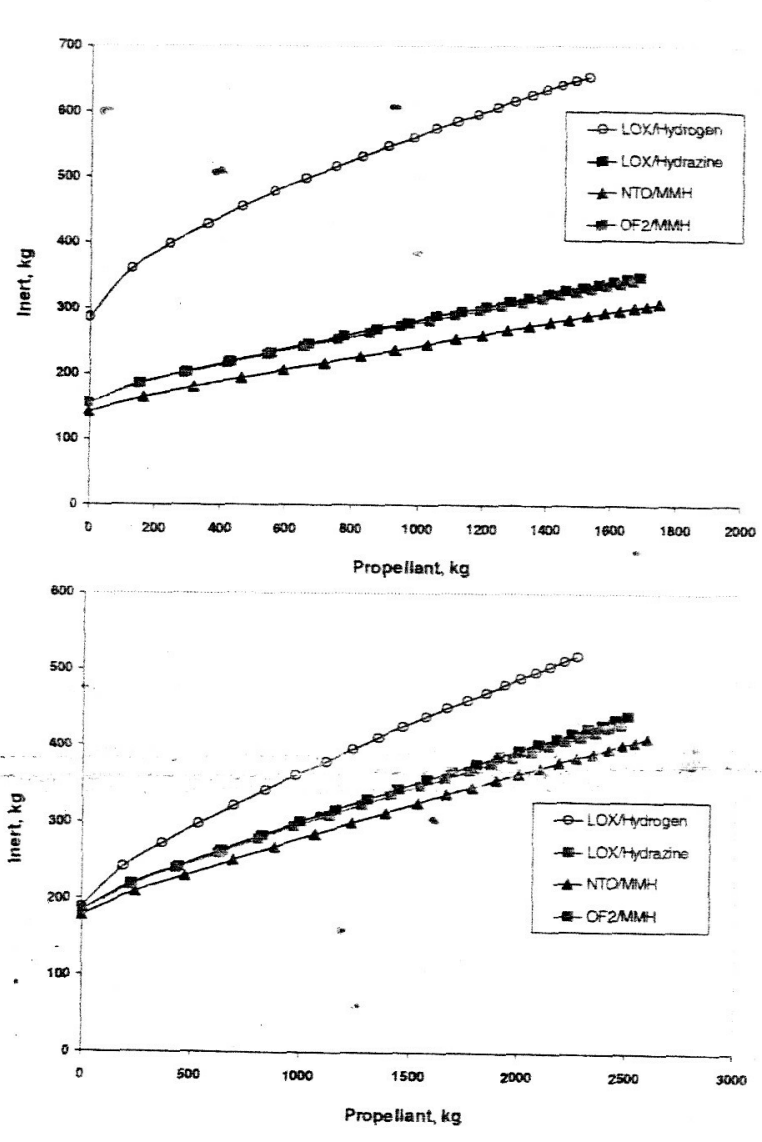

Figure 8 Propulsion System Inert Mass Trends

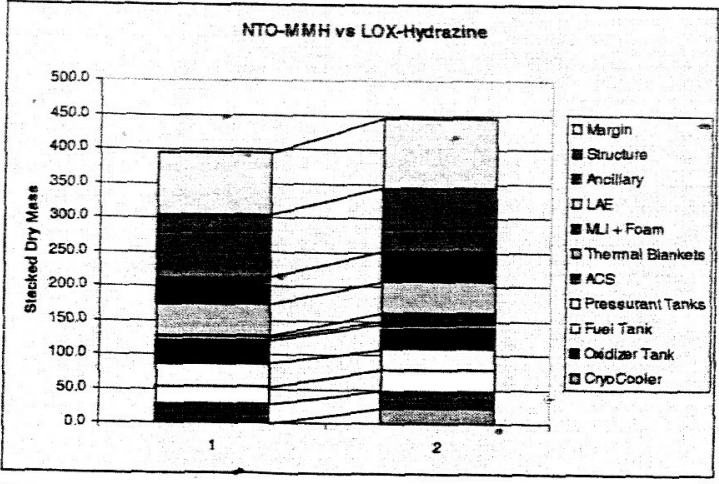

Figure 9 Inert Mass Comparison, Storables vs LOX-Hydrazine

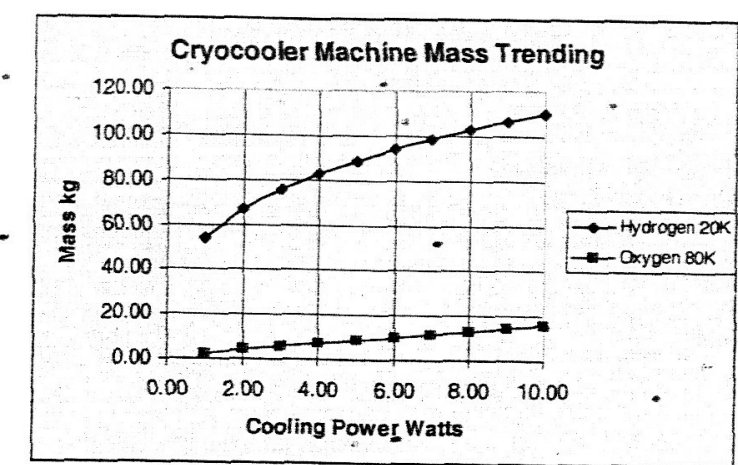

Figure 10 Cryocooler Mass Trending

Over $90 \%$ of the penalty is associated with the hydrogen cryocooler. The effects of the mass penalty on payload are reduced if the cryocooler and its support equipment can be jettisoned before the propelant is used. This may be feasible for some of the more challenging missions that benefit from cryogenic propulsion because these missions involve one major propulsion maneuver, such as planetary capture, perhaps followed in a few hours or days by further maneuvers, after which the propulsion system is not used.

Accordingly, there are 5 cases of interest for LOX-hydrogen, in-ascending order of technology: 
1. Pressure-fed, full cryocooler mass penalty

2. Pressure-fed, jettison cryocooler power and thermal systems (may be easier than jettisoning the cryocooler itself, since the latter must make intimate thermal contact with the well-insulated propellant tanks)

3. Pressure-fed, jettison entire cryocooler system

4. Pump-fed, jettison entire cryocøoler system

5. Pump-fed, no cryocooler (short duration mission)

Figure 13 shows the effect of these variations, relative to the baseline, for a median-size system with start mass (including payload) $3000 \mathrm{~kg}$. The cryogenic system varies from worst to best performer, depending on the technology level.

There is also a significant size effect, as illustrated in Figure 14. Here, the median technology level (3, pressure-fed, jettison entire cryocooler) is compared for start masses of 1000 and $5000 \mathrm{~kg}$. Again, the cryogenic system varies from worst to best performer. The change is mainly due to reducing dominance of thermal insulation mass as the propellant load and tank size increase.

Figure 15 presents an inert mass comparison between a pressure-fed cryogenic system and the storable baseline. For the pump-fed cryogenic system the propellant and pressuant tank penalties are much less, but the other differences change very little:

Literature review indicates (1) such a pump can be built, but will be exploring new ground; (2) the best approach is a conventional turbopump.

Exotic propellants offer moderate performance increases, and merit further evaluation. Their typically high combustion temperature raises doubts as to realization of high Isp potential, and this in particular needs assessment. LOX-hydrazine comes within $20 \mathrm{sec}$ of $\mathrm{OF}_{2}-\mathrm{MMH}$ at chamber temperatures $660 \mathrm{C}$ less. We note that the contemporary iridium-coated rhenium combustion chamber technology was originally developed for use with fluorine. Further examination of fluorine-hydrazine is recommended, since better performance at acceptable - combustion temperatures may be achieved. The boiling point of fluorine is about $85 \mathrm{~K}$ versus $125 \mathrm{~K}$ for $\mathrm{OF}_{2}$. In most applications this won't make much difference.

Advanced Monopropellants - In smaller systems with moderate delta $\mathrm{V}$ requirements, they (advanced monopropellants) perform about as well as other propellants/systems evaluated. The simplicity of only one propellant is attractive. Note in the Telemachus perihelion performance discussed below, monopropellant performs about as well as the other options.

These systems need a catalyst bed or ignition system. Once ignited, they probably do not need a catalyst to continue combustion. For single-bum missions they may be particularly attractive. They may not be as suitable for attitude control propellants (low thrust, small impulse bit). Thus they may not be so attractive where an NTOhydrazine system can fulfill both functions.

Gelled Propellants - Propulsion system geometry for the tactical missile application is cylindrical (Fig. 16), ideal for a missile but problematical for some spacecraft propulsion systems. (It is, however, well suited to Mars ascent propulsion system geometry.) It would be useful to investigate feasibility of near-spherical tank geometries, especially efficient expulsion of gelled propellant. Brief discussions with investigators familiar with gelled

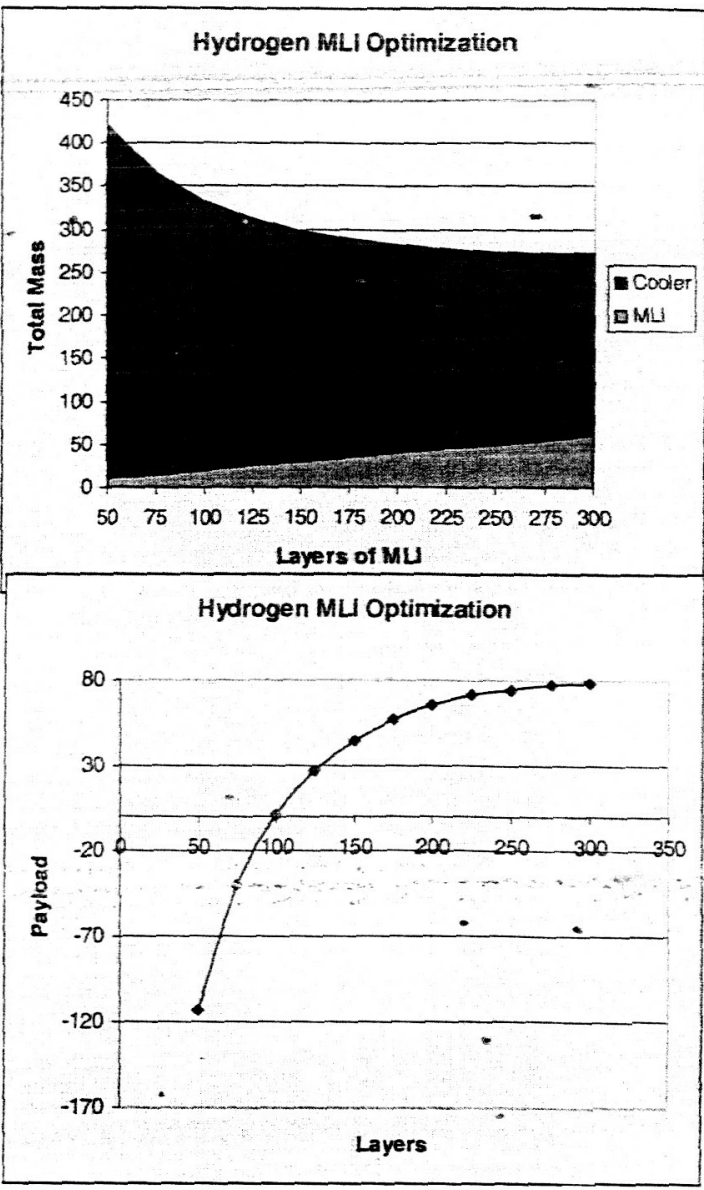

Figure 11 Hydrogen MLI Optimization

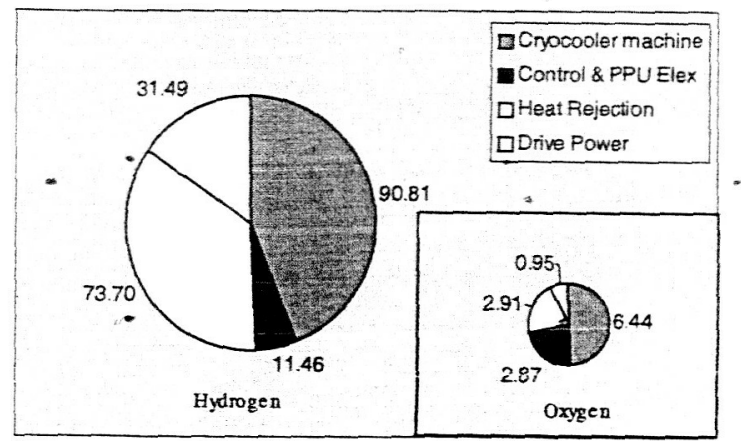

Figure 12 Power and Mass Distributions 
propellant state of the art indicated that a conventional positive expulsion device such as a bladder would work well for near-spherical tank geometry.

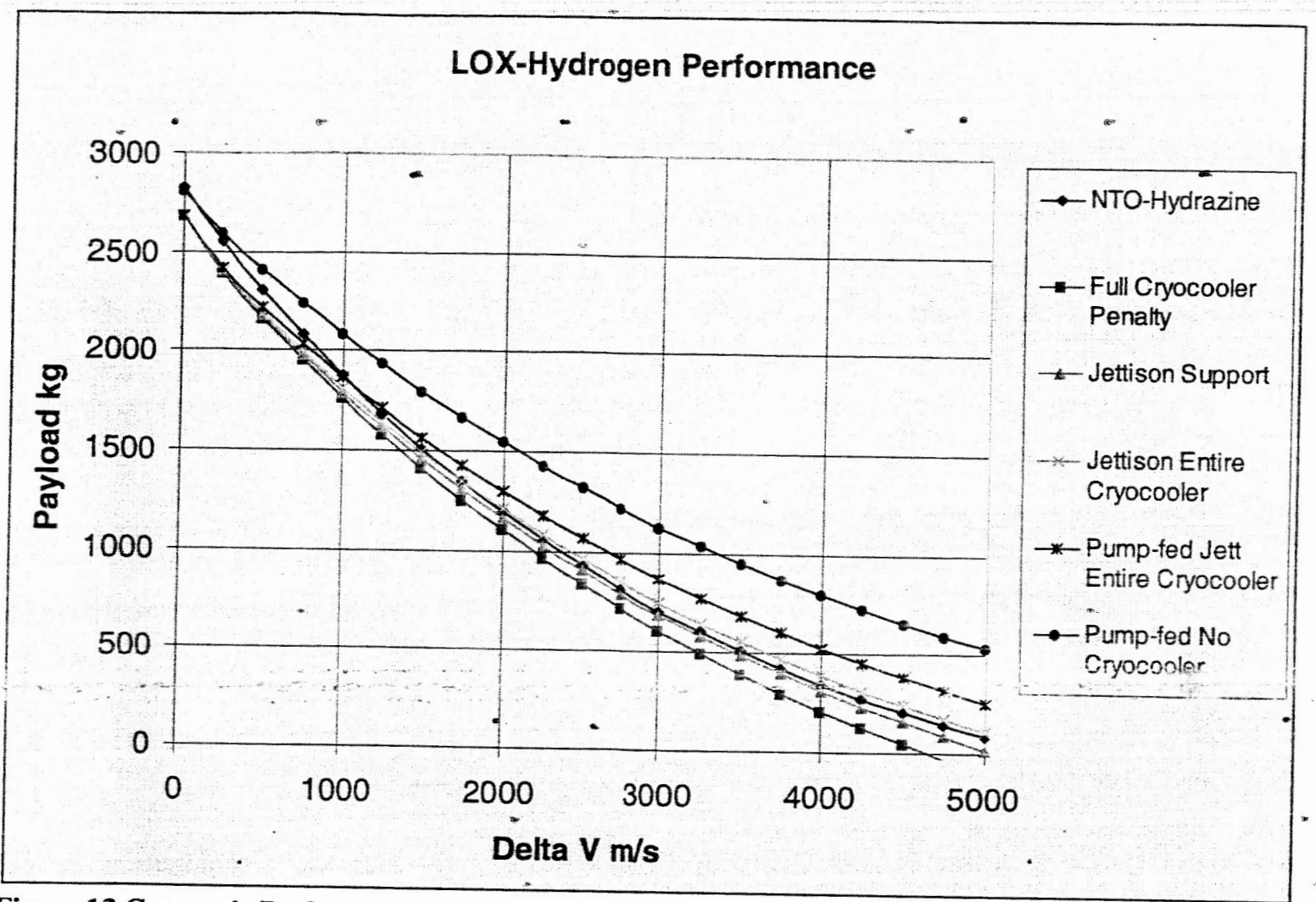

Figure 13 Cryogenic Performance Trending as a Function of Technology
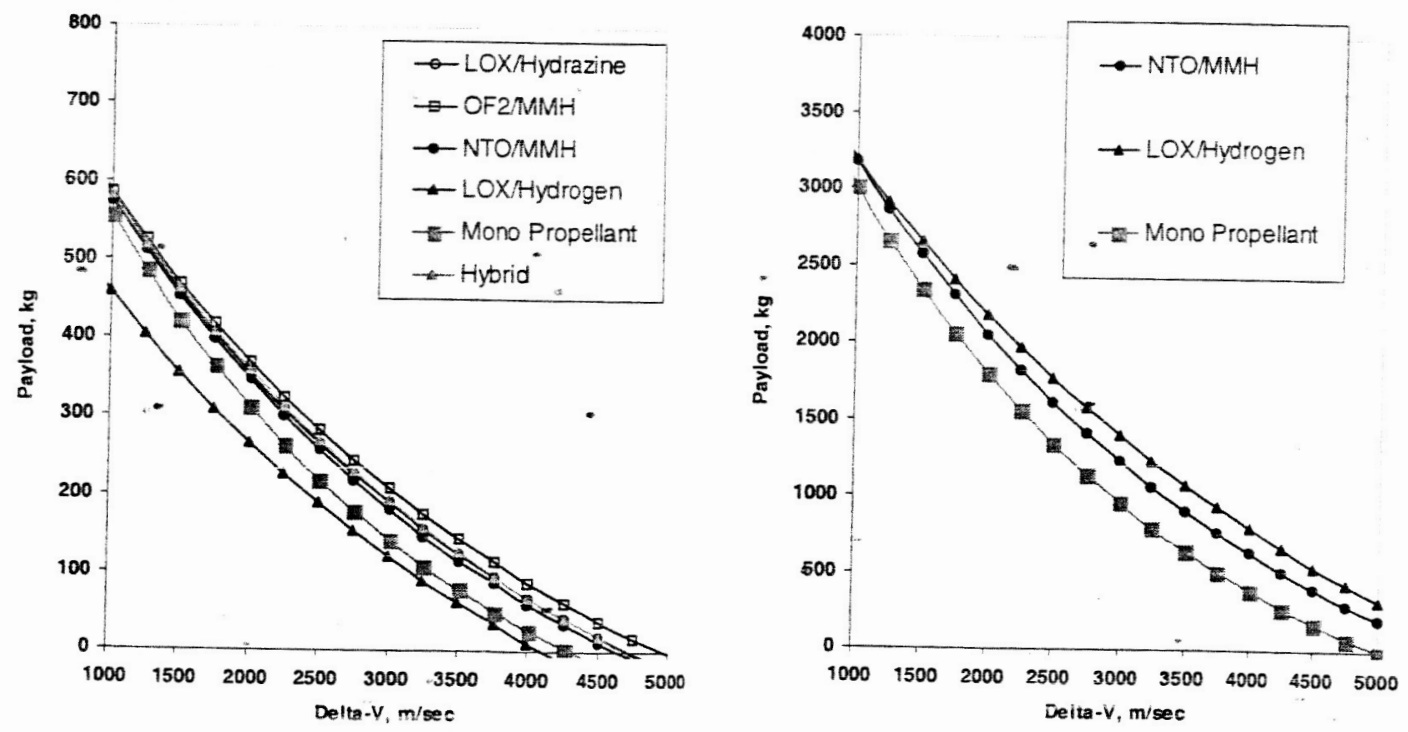

Figure 14 Cryogenic Periormance Trends for 1000 \& $5000 \mathrm{~kg}$ Start Mass 
SPGG pressurization is nominally only suited for one bum. (More than one SPGG could be used.)

Our evaluation is that gelled propellants are suited for planetary ascent propulsion and should be evaluated for that application, but may offer few advantages for inspace application. Cases where the gelled propellant can be allowed to freeze and then be thawed for use may show a system-level benefit. Current research is directed to capability to freeze and thaw gelled propellants; this would be a significant advantage for a Mars

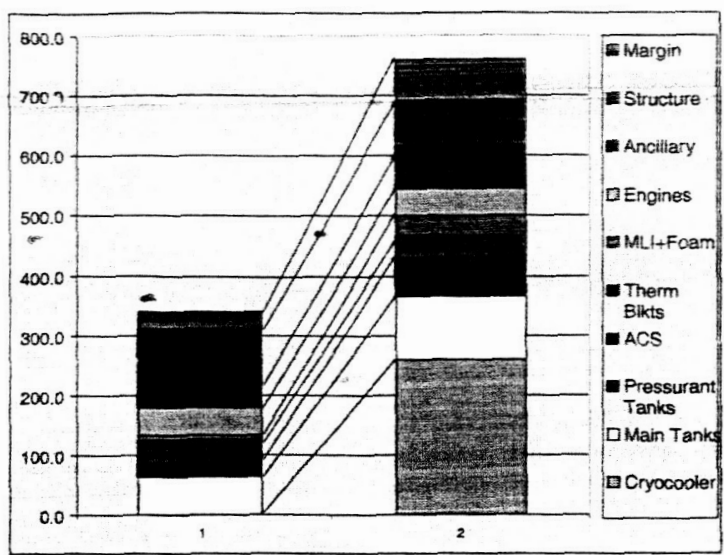

Figure 15 Inert Mass Comparison, Storable vs Cryogenic Propellants

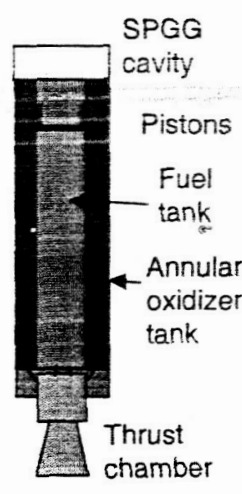

Figure 16 Gelled Propellant Geometry ascent system.

Specific Mission Applications - Propulsion comparisons are further illuminated by some of the specific applications analyzed during the study.

The C3 Topper burns immediately after launch vehicle separation to maximize benefit of Earth's gravity-field. A cryocooler is not required for a cryogenic stage since duration is quite short. Starting total mass will be on the order of 5 to $10 \mathrm{t}$. Thrust required is 15 to $25 \mathrm{kN}$ (3.to $5 \mathrm{klbf}$. The higher Isp of a jryo stage offers signt. atrt performance advantage cver a solid rocket motor as illustrated in Figure 17.

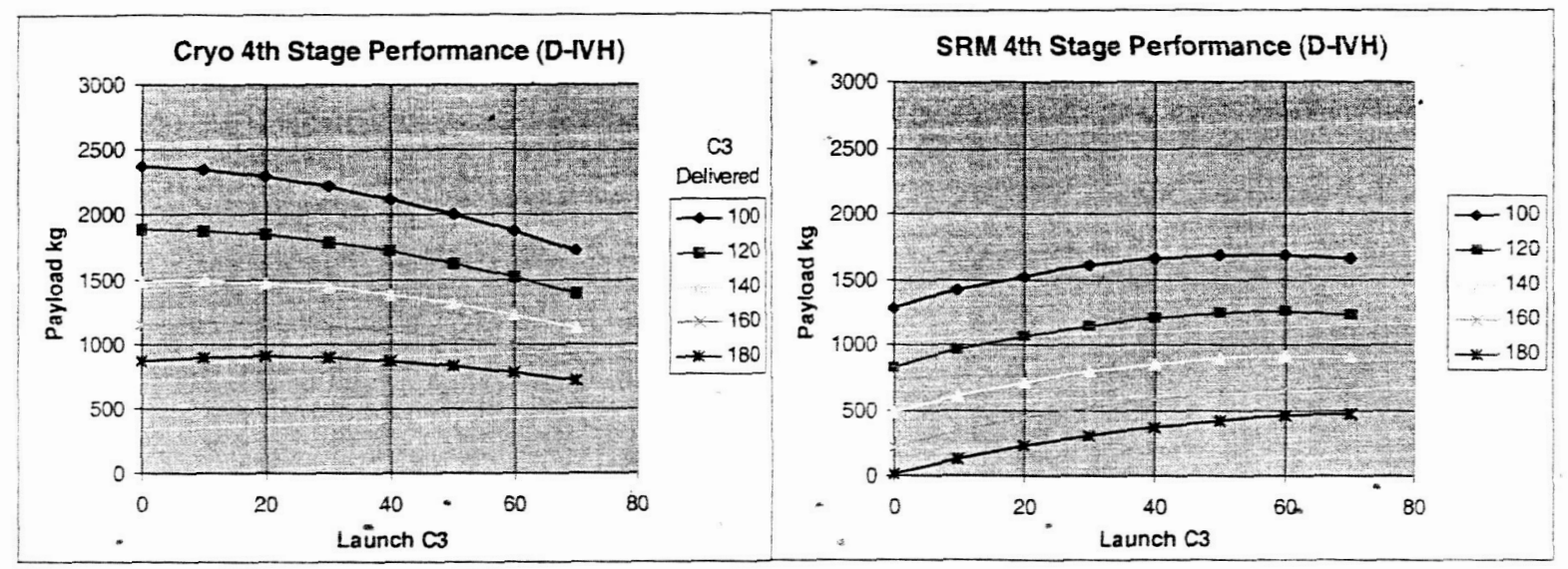

\section{Figure 17 Comparison of Cryogenic C3 Topper to Solid Propellant Rocket Motor}

The Telemachus mission has two major propulsion needs. A C3 Topper or an electric propulsion system eliminates the inner planet gravity assists of the baseline mission by enabling transfer direct to Jupiter, and saving several years of transfer time. Once arriving at perihelion, a further burn is required. Figure 18 shows a mass comparison of advanced chemical propulsion technologies for this maneuver. The monopropellant is the most logical alternative to the baseline bipropellant in view of its simplicity. Higher performing systems offer little performance advantage. We expect a similar result for Venus Aeronomy.

Several alternative mission profiles were evaluated for Neptune Orbiter. The baseline reference in this case is SEP-aerocapture, which can deliver about $1200 \mathrm{~kg}$ payload to the highly elliptic Neptune orbit. None of the advanced chemical options reach that performance capability. The best of the options evaluated could deliver about $600 \mathrm{~kg}$, assuming SEP/VGA delivery to Neptune transfer (eliminating need foraerocapture), as shown in Figure 19.

We found a non-nuclear option for Titan Sample Return, using two EELV heavy launches. The first delivers an aerocaptured spacecraft to Titan orbit, carrying the descent/ascent system. The second delivers another aerocaptured spacecraft to Titan orbit, carrying the return system. After the sample is acquired, the ascent system makes rendezvous with the return system and transfers the sample. The return system uses advanced chemical propulsion to depart Titan for return to Earth. The sample carrier performs Earth entry and landing similarly to current Mars 
sample return mission concepts. A cryogenic stage was preferred for this application, but a storable propellant stage could do the return with a longer trip time.

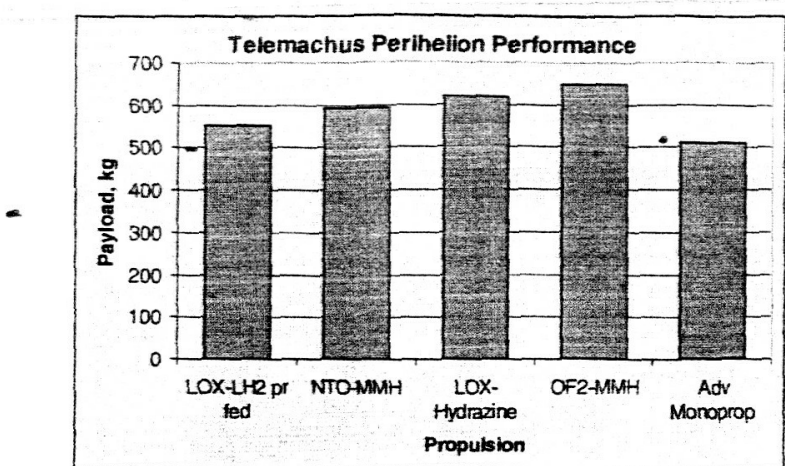

Figure 18 Propulsion Performance Comparison for Telemcahus Perihelion Burn

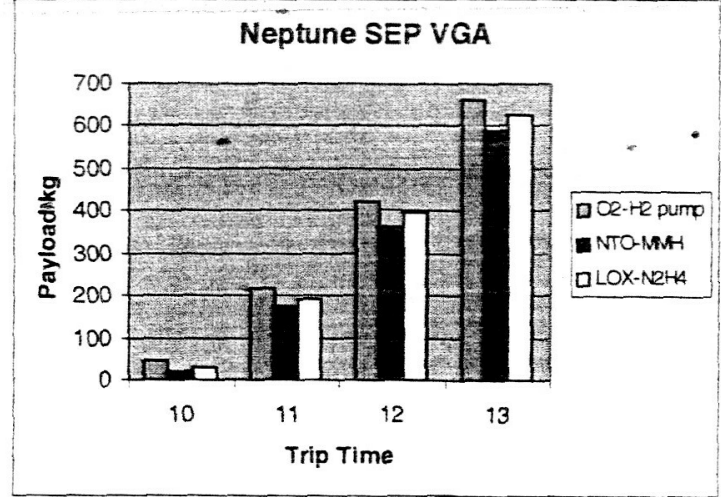

Figure 19 Propulsion Performance Comparison for Neptune Capture (Trip times in years)

\section{Indications and Conclusions}

Many of our conclusions were preliminary, or regarded as indicative only, since this was hritet stids utendeo to pont the way for more detailed work: In general, chemical propulsion is a mature tecnnology and the improvemerts identified, while significant, are not dramatic.

The most promising applications for advanced chemical propulsion appeared to be those where high performance is needed, and in those cases the highest-performing propulsion options appeared to offer the greatest benefit. LOX-hydrogen offers best performance, if (1) cryocooler mass penalty can be ameliorated, and (2) a pump- . fed engine is developed, to reduce mass penalties associated with hydrogen pressurization and increase Isp. The simplest application for LOX-hydrogen is a small upper stage for launch vehicles (the "C3 Topper"). This extends the C3 capability of current EELVs to about 200, albeit with less and less payload as C3 is increased. The benefits are appreciable beginning at $\mathrm{C} 3$ about 40 . Without a $\mathrm{C} 3$ topper, EELV payload goes to zero at $\mathrm{C} 3$ less than 100. The cryogenic C 3 topper offers payload increase over a solid rocket about $50 \%$ to $60 \%$.

Significant technology needs, beyond small turbopumps, for hydrogen use are development of thick MLI, and improvements in cryocooler mass and efficiency. Performance advantages for LOX-hydrogen depend on these technology advances; without them, its performance was less than current technology.

After LOX-hydrogen, the best performers were $\mathrm{OF}_{2}-\mathrm{MMH}$ and LOX-hydrazine in that order. If LOX-hydrogen technology is not developed, or experiences delays or difficulties, fluorine-bearing oxidizers should be given serious consideration. Fluorine-hydrazine may prove a better option than $\mathrm{OF}_{2}-\mathrm{MMH}$. LOX-hydrazine offers modest performance advantages, and may be of particular interest for short-duration missions for which cryocoolers are not needed, or if a passive cooling method can be developed.

We spent relatively little effort on hybrids. Hybrids with metal hydride.additives may offer Isp $\sim 350$. If so, they may be competitive. This class of hybrids should be regarded as high risk, high payoff. Modest-scale testing to confirm performance potential might prove relatively inexpensive, and would go a long way towards assessing the payoff potential.

Advanced monopropellants appeared promising for modest performance applications. At Isp $>=275$, performance about equals state-of-art biprops, and systems are simpler. Whether they would be more reliable needs to be assessed. Catalysts and/or ignition remain a technology issue.

Gelled propellants appear mainly of interest to planetary ascent. However, if gels can increase the propellant storage temperature, they could be of interest for missions nearer the Sun. Also, if gels can permit long-period freezing of propellants on trajectories to the outer planets, they may simplify spacecraft/propulsion thermal design for these missions.

\section{References}

1. Falk, A. Y., Clapp, S. K., and Nagal, C. K., Space Storable Propellant Performance Study, NASA CR-722487, Nov. 1968. 
2. Schneider, S. J., On-Board Propulsion System Analysis of High Density Propellants, AIAA Paper No. 98-3670, $34^{\text {th }}$ AIAA/ASME/SAE/ASE Joint Propulsion Conference and Exhibit, July 13-15. 1998. Cleveland, OH.

3. Schmidt, H. W., Handling and Use of Flourine and Fluorine-Oxygen Mixtures in Rocket Systems, NASA SP$3037,1967$.

4. Bond, D. L., Appel, M. A., and Kruger, G. W., Fluorine-Hydrazine Propulsion Technology Update, The 1980 JANNAF Propulsion Meeting, Vol. 5, pp. 147-164.

5. Personal Communication, B. Reed, NASA Glenn Research Center, August, 2003.

6. Stultz, J. W., Thermal Analysis of High-Energy Propulsion System for a Rover Class Mars Orbiter, AIAA Paper No. 78-888, $2^{\text {nd }}$ AIAA/ASME Thermophysics and Heat Transfer Conference, Palo Alto, CA, May, 1978

7. Dunn, S., Coates, D., and Nickerson, G. (1999), TDK99 Two Dimensional Kinetics (TDK) Nozzle Performance Computer Program User's Manual, SEA Inc.

8. Reed, B. R. and Schneider, S. J., Hydrogen/Oxygen Auxiliary Propulsion Technology, AIAA Paper No. 91-3440, Conference on Advanced Space Exploration Initiative Technologies, Sept. 4-6, 1991, Cleveland, OH (also NASA TM 105249).

9. Honda, L., Calvignac, J., and Matuszak, L., Storable Thruster Technology Program-Mission Study, JANNAF 2002.

10. Plachta, D. and Kittel, P. An Updated Zero Boil-off Propellant Storage Analysis Applied to Upper Stages or Depots in a LEO Environment, AIAA 2002-3589, 36 ${ }^{\text {th }}$ AIAA/ASME/SAE/ASEE Joint Propulsion Conference and Exhibit, July 7-10, 2002, Indianapolis, IN.

11. ter Brake, H. J. M. and Wiegerinck, G. G. M., Low-power Cryocooler Survey, Cryogenics, 42 (2002), pp. 705718.

\section{Neptune Orbiter.}

\section{SEP/Aerocapture Baseline}

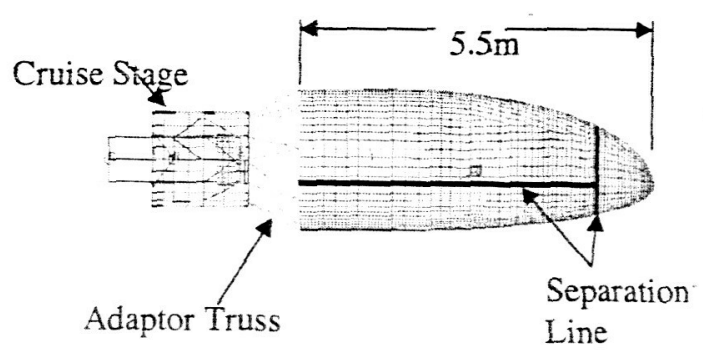

- SSE Long-Term Mission (after 2013)

- Mission Objectives.

- Orbit Neptune, visit all major parts of

Neptune system

- Cassini-like science investigation of the Neptune system

- Neptune atmosphere, interior, fields

- Many Triton flybys/gravity assists

- Nereid flyby upon approach

- Small inner satellites

- Rings

- Significant orbit evolution over mission lifetime: "Tour"
- Mission Requirements

- Sciencecraft requirements

- Payload: mass, power, (data volume?)

- Driving observation accommodations

- NAC pointing \& stability during ?500 km

Triton flybys

- Telecom; Cooled IR focal plane

$-? 2$ years in Nepture orbit

- Cruise "not much more than 10 years"

Neptune Orbit: $4000 \times 400,000$ (alt's) $157.3 \mathrm{deg}$ incl.

Mission Payload $500 \mathrm{~kg}$ Orbiter $+75 \mathrm{~kg}$

monopropellant [for periapse raise if aerocapture;

otherwise est. $40 \mathrm{~kg}$ ]

Target Launch Date 2010

Mission architectures/transportation

\section{challenges}

- Multiple gravity assists incl Jupiter to Neptune

- Cruise time for most trajec. over 10 years

-SEP tö fast Neptune transfer; arrival V, ? 15

$\mathrm{km} / \mathrm{s}$; Capture ? $V>5 \mathrm{~km} / \mathrm{s}$

- Options

-SEP/Aerocapture

- SEP/Advanced Chem.

- [NEP]

- MXER Tether/Adv. Chem

- Solar Sail/Aerocapture 


\section{Venus Aeronomy Probe}

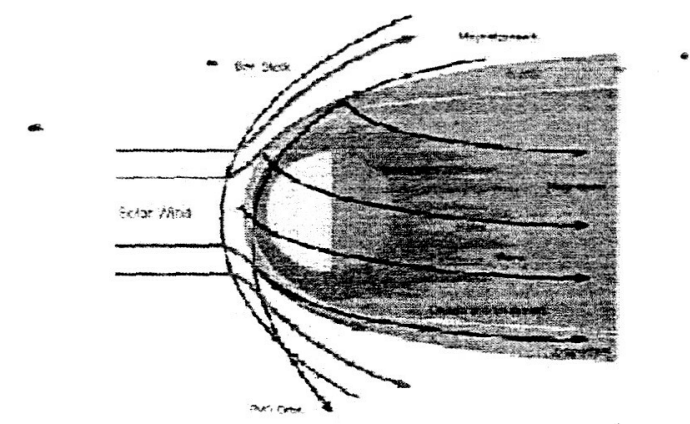

SEC Mission

\section{Science Objectives}

- Determine Mechanisms for Energy Transfer From Solar Wind to lonosphere and Upper Atmosphere - Measure Charged Particles Responsible for Aurora!-Type Emissions and Infer their A.cceleration Mechanisms

- Eetermine Formation Processes for lonospheric Magnetic Flux Ropes, Ionospheric "Holes" on the Nightside and the Loss of Ionospheric Plasma in the Form of Streamers, Rays and Clouds
Mission Description

- Example Mission Design

- Small Delta II

- Kear Flight Time, 1year OPS

- High Inclination Elliptical Orbit

- $150 \mathrm{~km} \times 12,000 \mathrm{~km}$

- Flight System Concept

- Spin-Stabilized Platiorm

- Floating Potential Neutralization

- Solar array power

- Mass Unk. probably tens of kg science payload

\section{Target Launch Date Unknown}

\section{Mission architectures/Transportation challenges \\ - Launch direct to Venus; propulsive capture into elliptic orbit}

\section{Options}
- Aerocature.
- Advanced Chem; good example of small advanced chem system
- MXER Tether/Adv. Chem

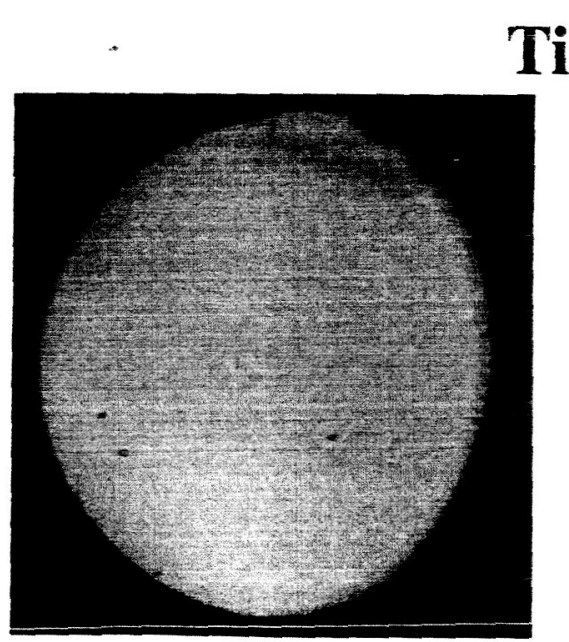

- SSE mid-term mission (Project start after 2005)

- Mission Objectives

- Orbiter and in situ element at Titan

- Detailed investigation of Titan and its organic environment

- Global high-resolution IR \& SAR mapping

- Global measurements of gross surface

morphology, composition, chemistry

- Atmospheric composition, structure, dynamics

- Composition \& distribution of organics, organic chemical processes, context, \& energy sources

- Pre-\& proto-biological chemistry

\section{Titan Explorer}

- Mission Requirements

- Sciencecraft requirements

- Payload: mass, power, (data volume?)

- Driving observation accommodations

- Telecom

- Cooled IR focal plane

$-S A R$

$-? 2$ years in Titan orbit.

- One year in situ element lifetime

-Cruise time?

- Mission architectures / Transportation challenges - Inner SS / Jupiter gravity assists to Titan

- Cruise time for most trajectories 8 years or less

-SEP transfer to Saturn; arrival $\mathrm{V}_{?}$ ? ? km/s

- Aerobraking $\mathrm{V}_{\mathrm{rel}} 6-10 \mathrm{~km} / \mathrm{s}, ? \mathrm{~V}>4-8 \mathrm{~km} / \mathrm{s}$

-JGA tends to yield higher encounter velocity at Titan

- Transportation options

- Gravity assist or SEP to Saturn system

- Rigid aeroshell or ballute aerocapture

-Propulsive capture 


\section{Titan Sample Return}

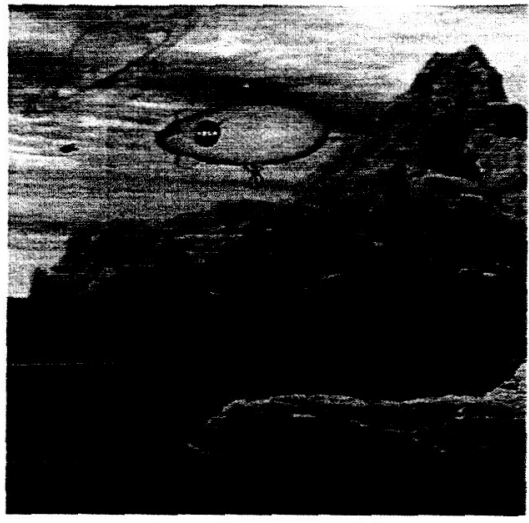

Long-Term SSE Mission

Science Objectives

- Obtain selected surtace samples, including "pre-biotic" material if it exists on Titan

- Each sample in its own container. and identified as to bcation and situation where sampled

- Maintain Titan surface temperature throughout return mission
Mission Requirements

Titan orbit $1800-2000 \mathrm{~km}$

Short surface stay time?

RTG required on lander, or can we get by with batteries?

Titan orbit rendezvous with sample container transfer

Propulsive return to TEI; spacecraft supports

Earth lander (power, GN\&C)

Direct entry landing at Earth, passive lander

\section{Transportation Challenges}

- Achieving trip time (high delta Vs)

- Ascent from Titan through deep atmosphere

- High approach velocity

- Outer solar system lack of energy source (foi propulsion)

- In-space baseline is NEP.

\section{Solar Probe}

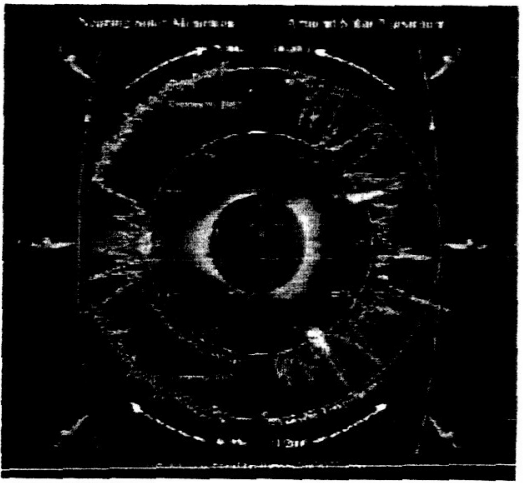

Science Objectives

- Determine acceleration processes and find source regions of fast/slow solar wind at min/max solar activity - Locate the source and trace the flow of energy that heats the corona

- Construct 3-D coronal density configuration from pole to pole; determine subsurface flow pattern and structure of polar magnetic field and its relationship with the overlying corona

- Identify acceleration mechanisms \& locate source regions of energetic particles; determine the role of plasma waves and turbulence in the production of solar wind and energetic particles

\section{Mission Description}

- Mission Design

- Launch opportunity every 13 months (baseline is May 2010 launch)

- Two solar passes (polar, 4 RS) within $7.1 \mathrm{yr}$; three within $11.1 \mathrm{yr}$

- Atlas 551/Star-48B launch; $713 \mathrm{~kg} @$ C3 $128 \mathrm{~km}^{2} / \mathrm{s}^{2}$

- JGA traj.,post-perihelion DV for successive passes

- 3.1-yr cruise; $0.02 \times 5$ AU final orbit with period $4 \mathrm{yr}$

- Plight System Concept

- $15^{\circ}$ half-angle carbon-carbon heat shield

- 3-axis stabilized with $0.2^{\circ}$ pointing control and $0.05^{\circ}$ knowledge

- RTG power source ( 3 Multi-Mission RTGs supply 330 W BOL)

- Ka-band downlink, X-band uplink, 34-m DSN dishes - Data rate: up to $40 \mathrm{kbps}$ real-time with $200 \mathrm{kbps}$ additional stored data

\section{Transportation Options:}

Advanced Chem or SEP to replace Star-48B Alternatives to JGA do not appear reasonable 


\section{Telemachus}

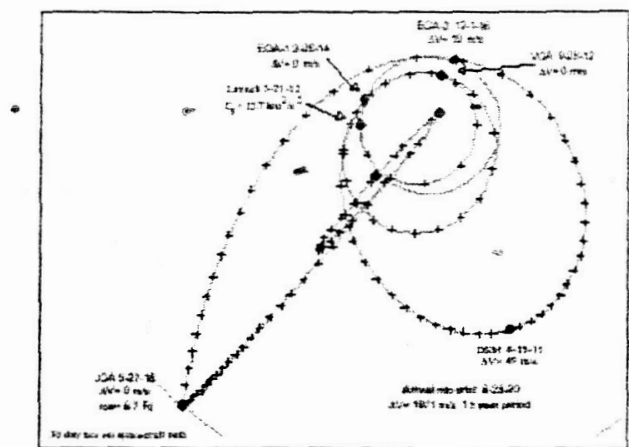

Science Objectives

- Understanding our changing Sun and its effects

throughout the Solar System (Space Science Enterprise

Strategic Plan, November 2000)

- Reveal through helioseismology how convection and

rotation couple \& magnetic flux accumulates in the polar regions (solar dynamo)

- Uncover the mechanism(s) in the polar regions of the Sun that accelerate the solar wind \& energetic particles and expel plasme and magretic fieldo'CMEst

- Exploit polar viewpoint to examine. distribution of radio and $x$-ray emission simultaneously from all solar longitudes - Determine the physics of the strongest stream/ stream plasma interactions and transient shocks where they are first formed in the heliosphere

\section{Mission Description}

- Example Mission Design

- Delta III Launch, $1765 \mathrm{~kg} @ \mathrm{C} 3=17 \mathrm{~km}^{2} / \mathrm{s}^{2}(12.7 \mathrm{~min})$ -

- VEEJGA Trajectory with Perihelion DV

-8.4 yr cruise, 3 yr science ops

- $0.2 \times 2.5$ AU Final Orbit, Period: 1.5 years $-90^{\circ}$

Heliographic Inclination

- 1st 4.5 years ecliptic (VEEJGA); 3 years in Fina!

Orbit (polar)

- Flight System Concept

- 3-Axis and Spin-Stabilized Platform

- Solar Arrays (Ultraflex, High Efficiency Silicon, High Temp Cells)

- Payload: 33 kg. 42 W. 8 kbps

$-2239 \mathrm{~m} / \mathrm{s}$ DV

- 30 arcsec (control), 10 arcsec (knowledge)

\section{Transportation Options}

- SEP or Adv Chem to obtain Jupiter trajectory directly without Earth or Venus gravity assist; also, advanced chem may benefit perihelion DV; note severe thermal environment Probably no reasunable alte ative 1 . coulu evaluate solar sail 